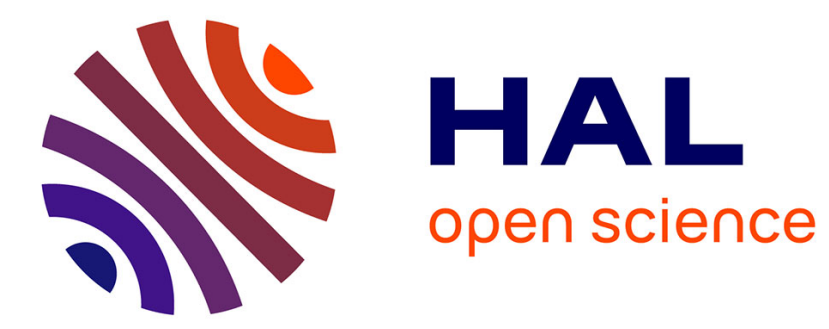

\title{
MICROSTRUCTURE EVOLUTION DURING SEVERE PLASTIC DEFORMATION
}

\author{
Sergiy Divinski, Anantha K Padmanabhan, Gerhard Wilde
}

\section{To cite this version:}

Sergiy Divinski, Anantha K Padmanabhan, Gerhard Wilde. MICROSTRUCTURE EVOLUTION DURING SEVERE PLASTIC DEFORMATION. Philosophical Magazine, 2011, pp.1. 10.1080/14786435.2011.615349 . hal-00746097

\section{HAL Id: hal-00746097 https://hal.science/hal-00746097}

Submitted on 27 Oct 2012

HAL is a multi-disciplinary open access archive for the deposit and dissemination of scientific research documents, whether they are published or not. The documents may come from teaching and research institutions in France or abroad, or from public or private research centers.
L'archive ouverte pluridisciplinaire HAL, est destinée au dépôt et à la diffusion de documents scientifiques de niveau recherche, publiés ou non, émanant des établissements d'enseignement et de recherche français ou étrangers, des laboratoires publics ou privés. 


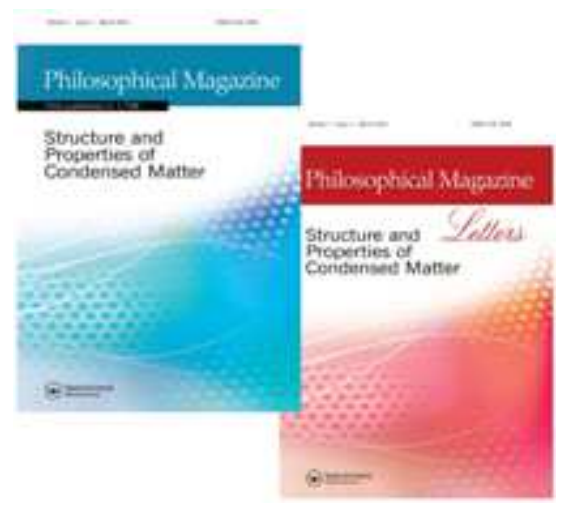

\section{MICROSTRUCTURE EVOLUTION DURING SEVERE PLASTIC DEFORMATION}

\begin{tabular}{|r|l|}
\hline Journal: & Philosophical Magazine \& Philosophical Magazine Letters \\
\hline Manuscript ID: & TPHM-11-Apr-0130.R1 \\
\hline Journal Selection: & Philosophical Magazine \\
\hline Date Submitted by the & $10-J u l-2011$ \\
\hline Complete List of Authors: & $\begin{array}{l}\text { Divinski, Sergiy; Institute of Materials Physics, University of } \\
\text { Muenster } \\
\text { Padmanabhan, Anantha; University of Hyderabad, Centre for } \\
\text { Nanotechnology and School of Engineering Sciences \& Technology } \\
\text { Wilde, Gerhard; Universität Münster, Institute of Materials Physics }\end{array}$ \\
\hline Keywords: & ECAP, dislocations, grain boundary diffusion, fracture \\
\hline Keywords (user supplied): & severe plastic deformation \\
\hline \multicolumn{2}{|c}{} \\
\hline
\end{tabular}

\section{SCHOLARONE \\ Manuscripts}




\title{
MICROSTRUCTURE EVOLUTION DURING SEVERE PLASTIC DEFORMATION
}

\author{
Sergiy V. Divinski ${ }^{1, a}$, K Anantha Padmanabhan ${ }^{1,2, b}$, Gerhard Wilde ${ }^{1, \mathrm{c}}$ \\ ${ }^{1}$ Institute of Materials Physics, University of Münster, Wilhelm-Klemm-Str. 10, 48149 Münster, \\ Germany \\ ${ }^{2}$ Centre for Nanotechnology and School of Engineering Sciences \& Technology, University of \\ Hyderabad, Hyderabad 500 046, India \\ adivin@uni-muenster.de; ${ }^{b}$ kapse@ $@$ uohyd.ernet.in; ${ }^{c}$ gwilde@uni-muenster.de
}




\title{
MICROSTRUCTURE EVOLUTION DURING SEVERE PLASTIC DEFORMATION
}

\begin{abstract}
Radiotracer diffusion studies of severely deformed, ultra-fine grained materials have revealed the presence of ultra-fast transport paths, which include "non-equilibrium" grain boundaries and free volume. Under some experimental conditions, percolating porosity is produced even in pure copper [Ribbe et al., Phys. Rev. Lett. 2009]. Micro-cracks may form in metals, if the local maximum shear stress exceeds the shear yield stress [Dieter GE. Mechanical metallurgy, McGraw-Hill, New York, 1986]. However, their growth and propagation is postponed till late in the deformation process because of the ductility of metals, the hydrostatic component of the stress system and/ or dynamic recovery/ recrystallization. That is, crack growth and propagation is present only when the scope for further deformation is highly restricted. Using this approach, the load required for equal channel angular pressing, the change in the slope of the Hall-Petch plot with decreasing grain size and the theoretical limit for the smallest grain size attainable in a metal in a SPD process are predicted and validated by experimental results. Experimentally successful prevention of percolated crack formation by the superposition of a hydrostatic pressure is also accounted for using this model.
\end{abstract}

Keywords: Severe plastic deformation; dislocation; grain boundary diffusion; fracture

\section{Introduction}

Severe plastic deformation (SPD) is an attractive route to produce bulk metallic materials with special combinations of properties $[1,2]$. It is believed that a small grain size, a relatively high fraction of high-angle grain boundaries (GBs) and the "special" state at least of some of them [2] are responsible for these properties.

In a coarse-grained material, with increasing deformation, the grain size decreases to a few hundred nanometers or a few tens of nanometers before saturation is reached. This (saturation) seems to be deformation- route-dependent. For example, in pure Ni deformed at room temperature a critical grain size of about $230 \mathrm{~nm}$ was reached after 12 passes of Equal Channel Angular Pressing (ECAP) [3]; $200 \mathrm{~nm}$ was the smallest grain size for High-Pressure Torsion (HPT) [4] and in contrast, a grain size of about $10 \mathrm{~nm}$ could be obtained for repeated cold-rolling [5]. A direct comparison is hindered by the differing purity of the materials used and the differences in the strain imparted. Moreover, strain localization in shear bands can affect the true total strain that can be imposed on a material by, e.g., HPT [6]. Nevertheless, we can 
conclude safely that in some instances a smallest grain size of several hundred nanometers is reached and continued straining along the same route does not often lead to further grain refinement [7-11]. On the other hand, the average grain size attained may also be one order of magnitude smaller for another processing route, i.e., $\sim 20 \mathrm{~nm}$ or less $[5,12]$. The smallest grain size achieved in SPD-processing depends on many details, such as the route (i.e., total strain, strain path, local strain rate and its distribution, flow pattern, details of repetitions, if present, etc.), overall strain rate (range), temperature, as well as the intrinsic properties of the material like stacking fault energy, alloying, etc., see e.g. [10, 13-14]. In spite of intense research, the origin of saturation in the grain size and the notable differences observed in the final grain size attainable in different metals and different routes of processing are not well understood.

Based on disclination-based deformation dynamics, Rybin has predicted a smallest grain size of about $200 \mathrm{~nm}$ for BCC metals [15]. Chuvildeev et al. considered the exhaustion of the relaxation paths for the accommodation of triple junction-related reactions as the reason for grain size saturation [16]. In contrast, Orlova et al. examined the relaxation of triple junction disclinations [17]. Glezer related it to the dynamic recovery processes occurring during severe plastic deformation [18]. With respect to Equal Channel angular Pressing (ECAP), Langdon has suggested an inter-relationship between the formation of sub-grain boundaries and shear deformation [19]. An attempt to predict grain size evolution was also made using a visco-plastic self-consistent polycrystalline model, combined with an empirical criterion for grain subdivision during ECAP [20, 21]. According to Mohamed [22] the minimum grain size is governed by a balance between the hardening rate introduced by dislocation generation and the recovery rate arising from dislocation annihilation and recombination. Blum has developed another dislocation-based model to account for the saturation grain size resulting from SPD processing $[23,24]$. There are also many other attempts dealing with different aspects of this problem, e.g. $[25,26]$. 
It is agreed that plastic deformation and dislocation activity give rise to a change in the microstructure state of general high-angle GBs in metals. According to Nazarov et al. [27], the large concentration of extrinsic non-equilibrium defects in "non-equilibrium" GBs enhances the GB diffusivity by increasing the accumulated free volume and GB excess free energy. The ultrafast diffusivity along some paths in SPD-processed materials is well documented [28, 29]. However, more recent studies, from our and other groups [29-32], have revealed an unexpected feature - a strong heterogeneity of the diffusion rates of general high-angle GBs in ECAPdeformed $\mathrm{Cu}$ and $\mathrm{Cu}$-rich alloys $[30,31]$. In well-annealed polycrystalline metals, the general high-angle GBs represent typically the fastest short-circuit diffusion paths [33]. But, even faster paths are observed in SPD processed metals with a hierarchy of internal interfaces with respect to their diffusion rates [32]. The most important and intriguing finding of these studies is the presence of (percolating) porosity, which is formed even in such highly ductile metals like ECAP-deformed pure copper [29]. This percolating internal porosity, which is reported in certain well-documented cases such as room-temperature ECAP-deformed pure $\mathrm{Cu}$ [34] and $\mathrm{Cu}$-based alloys [35] or HPT processed pure $\mathrm{Cu}$ [36] at room temperature, represents the fastest diffusion paths in an otherwise dense nanostructured material. Although the volume fraction of this porosity is extremely low, about a ppm, its presence in the given cases could be unambiguously established by the radiotracer technique due to the extreme sensitivity of the method and the volume-averaged information gained. This fact substantiates the importance of micro-cracking, which has to be taken into account, especially at very late stages of severe plastic deformation.

This paper presents a new viewpoint on severe plastic deformation in ductile metallic materials and relates the limiting, minimum grain size obtainable in the SPD of work-hardened metals to fracture processes that are analogous to those suggested in Cottrell's theory of plastic deformation-induced fracture [37]. As this limiting grain size is approached, crack initiation, propagation and fracture result. Using this concept, quantitative guidance can be extracted 
towards the selection of appropriate processing parameters to avoid crack formation during SPD. In addition, this theoretical investigation provides a basis for some of our earlier experimental findings [29-32, 38] and addresses the following questions:

- Why does a saturation grain size exist in such an unsteady, dynamic process like the SPD and how is this saturation grain size related to the material and processing parameters?

- What is the critical stress for the micro-cracking of a metal during the ECAP process?

- What is the relation between the processing parameters of SPD and the occurrence of "ultrafast" transport pathways that are related to percolated porosity and how can the evolution of the latter be controlled/ eliminated?

For successful technological applications, a bulk nanostructured material should not be deformed so severely that fracture processes are triggered. Alternatively, the straining may be done at elevated temperatures or combined with an intermediate annealing treatment. Understanding these limits is the practical reason for undertaking this study.

\section{A model for severe plastic deformation in UFG materials}

\subsection{Attainment of a minimum grain size in a UFG material}

We consider SPD processing, with focus on ECAP, HPT and accumulated roll bonding (ARB). Our description for predicting the smallest/ theoretical limiting grain size starts at a stage where dislocation propagation gets obstructed strongly due to grain refinement and work hardening. (Many earlier researchers have examined the region from the beginning of deformation till this stage.) We shall invoke a well-known idea in damage mechanics that when plastic deformation gets severely hampered, micro-crack formation and fracture processes could intervene. Till this stage, the yield stress, $\sigma_{y}$, would have increased with grain refinement in accordance with the Hall-Petch relation $[39,40]$ 


$$
\sigma_{y}=\sigma_{0}+\kappa d^{-0.5}
$$

where $\sigma_{0}$ is the resistance of the lattice to dislocation motion, $\kappa$ the strengthening coefficient the slope of the $\sigma_{y}$ vs. $d^{-0.5}$ plot - in general is a function of $d$, and $d$ is the grain size. This is because starting below about one micrometer average grain size, the slope of the Hall-Petch plot starts to deviate from its value for the coarse-grained regime to a lower, but positive value, which further decreases with more grain refinement until the stages where grain-size independence of yield stress and the inverse Hall-Petch effect are observed (the last stage is reached when the grain size is less than about $15-10 \mathrm{~nm}[41-50]$.

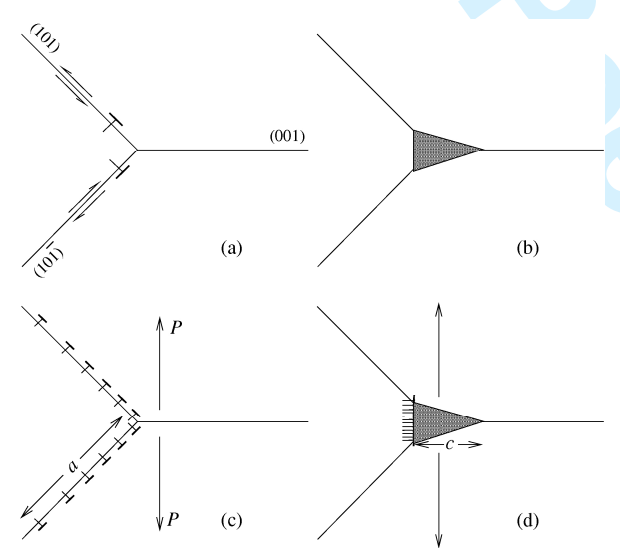

Figure 1. Cottrell's model [37] for plasticity-induced cracking process: Coalescence of two slip directions (a) to form a cracked dislocation on a cleavage plane (b); and coalescence of two slip bands (c) to form a cleavage crack (d). This model was derived for BCC metals $[37,51]$.

During SPD, depending on the homologous temperature of deformation, strain and strain rate, recovery processes could be present or absent ${ }^{1}$. The following analysis applies equally to both the cases, so long as in the former case also work hardening effects dominate over recovery processes, i.e., the work hardening rate will be positive in both cases, although it would have a lower value if recovery is present. We assume that the onset of initial micro-crack formation in a local region is governed by a description analogous to what is presented in Cottrell's theory of brittle fracture of BCC metals, which involves plasticity-induced crack initiation and propagation

\footnotetext{
${ }^{1}$ There is experimental evidence for the triggering of recovery processes at late stages in deformation (i.e., at large strains) when the grain size reaches close to its saturation value, see e.g. Ref. [52]. They are important in metals like $\mathrm{Cu}$ subjected to SPD.
} 
[37], Fig. 1. It should be noted that Fig. 1 considers both situations where pile-up formation is absent or present.

A variant of this model for an FCC metal could be the formation of the experimentally well-established Lomer-Cottrell sessile dislocation (Lomer-Cottrell lock), see Fig. 2 [53]. This mechanism is known to cause work hardening in FCC metals. During the late stages of severe plastic deformation, when the stress is already close to the fracture stress of the material and if further work hardening is present, it will raise the local shear stress to a value equal to or above the fracture shear stress of the material. Then, the edge of the wedge - the Lomer-Cottrell sessile dislocation (Fig. 2) - would open up and a crack would result.
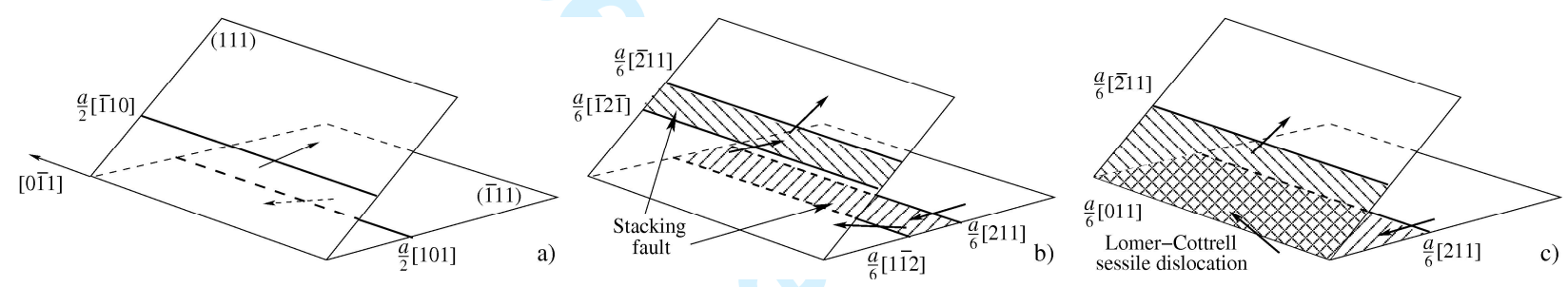

Figure 2. Formation of a Lomer-Cottrell sessile dislocation in FCC metals, a) - c) (after Hull [53]).

In the model of Cottrell [37], this process is governed by the equation

$$
\tau_{y}=\frac{\beta G \gamma_{s}}{\kappa d^{-0.5}} ; \beta \cong 1 ; \quad \text { whence } \kappa=\frac{\beta G \gamma_{s}}{\tau_{y} d^{-0.5}} \text {. }
$$

Here $\tau_{y}$, the shear yield stress $(\approx$ shear fracture stress) is approximately equal to one half of the tensile yield stress, $\sigma_{\mathrm{y}}(\approx$ tensile fracture stress), at the location where a crack is initially formed, $\gamma_{s}$ the specific surface energy for "brittle" fracture in metals and $G$ is the shear modulus [51]. For the tensile mode, $\beta=0.5[37,51]$. Solving Eq. (2) with respect to the grain size $d$, we obtain

$$
d_{c}=\left(\frac{G \gamma_{s}}{\kappa \sigma_{y c}}\right)^{2}
$$


Assuming that this equation is valid for the FCC structure also (where Fig. 2 describes the fracture initiation process, instead of Fig. 1), we identify $d_{c}$ as the smallest attainable grain size at a given temperature and strain rate, which is reached at the critical stress $\sigma_{y c}$ as fracture starts in a region of maximum stress concentration. Understandably, at this near-terminal stage of deformation, both $\kappa$ and $d_{c}$ depend on parameters associated with plastic deformation and fracture $\left(\sigma_{y} / \sigma_{y c}\right.$ and $\gamma_{s}$ respectively). This derivation is general enough to apply equally well to different SPD processes, e.g., ECAP, HPT, ARB. Evidently Eqs. (1)-(3) are derived assuming a uniaxial stress state. Generalisation to the 3D situation, once the stress state in each of the SPD processes becomes known, will follow the procedures of engineering plasticity, which can be found in books on that subject, e.g., [54]. Regardless of the yield criterion used, e.g., von Mises, Tresca, Mohr-Coulomb, Drucker-Prager, Gurson, the uniaxial stress will have to be multiplied by a factor of the order of unity to obtain the equivalent stress for the new situation.

The key point of the present model is the creation of a crack by plastic deformation at a point of stress concentration. There are several publications in which experimental evidence for dislocation pile-ups and forests in severely deformed FCC metals has been presented, e.g. [5557]. With decreasing grain size, the density of dislocations increases strongly and their interactions prevent reliable observations in TEM experiments. However, one meets with difficulties in case of FCC metals with high stacking fault energy and some other materials, where dislocation pile-ups may not form.

For such cases, Fig. 1a and Fig. 2 (depending on whether the metal has a BCC or FCC structure), which do not require a dislocation pile-up, could be considered. It should be noted that the Hall-Petch relation, implicit in Cottrell's analysis, could also be derived using ideas like geometrically necessary dislocations put forward by Ashby [58], Kocks [59] and Hirth [60]. The specific microscopic details of dislocation density evolution, which give rise to the Hall-Petch 
relation, are beyond the scope of this approach and are available in the works of Estrin and coworkers [61, 62], Zehetbauer [63] etc.

The variation of $d_{c}$ with temperature is reflected in the model via the temperature dependence of $\sigma_{y c}$, which increases near-exponentially with a decrease in test temperature, while the increase in the value of $G$ with a decrease in temperature is approximately linear [64]. Experimental evidence for this conclusion, i.e. temperature dependence of $d_{c}$, is available (see, for example, [65]).

On the other hand, experimental evidence for the tendency towards fracture in ductile metals in this fashion is seen in the propagation of a series of cracks along a line connecting several of such micro-cracks in ECAP-processed $\mathrm{Cu}-1$ wt. \% $\mathrm{Pb}$ alloy, deformed by 4 passes according to the route $\mathrm{B}_{\mathrm{C}}$, see Fig. 3a. Such lines that connect the plasticity-induced cracks might eventually form the grain boundaries of the terminal, theoretical grain size.

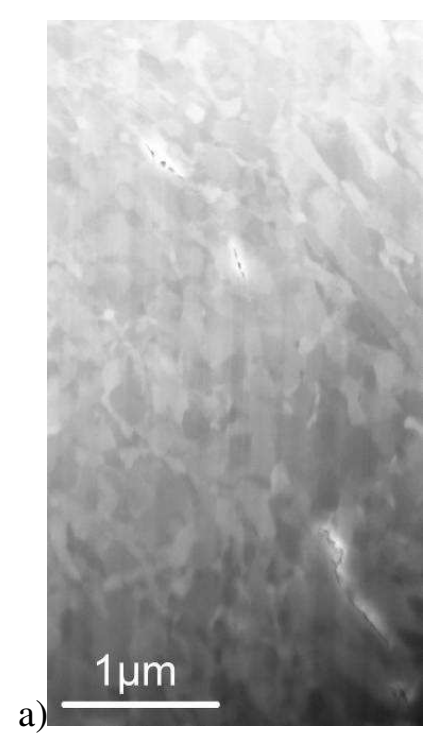

b)

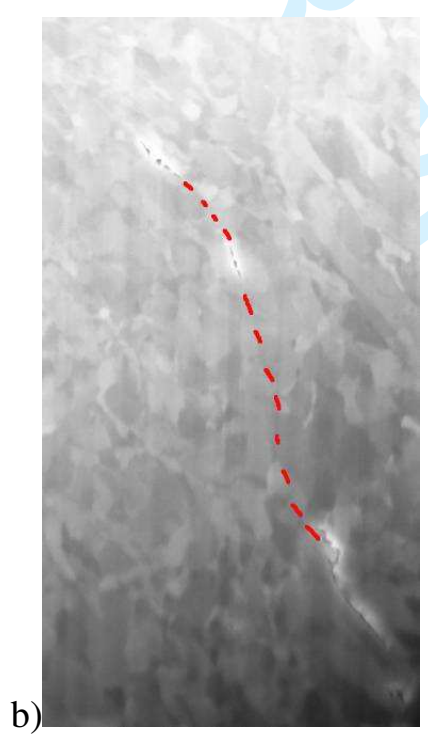

Figure 3. SEM image of a vertical section of ECAP-deformed $\mathrm{Cu}-1$ wt. $\% \mathrm{~Pb}$ alloy produced by FIB; a chain of micro-cracks is observed (a). The microstructure may be interpreted as displaying cracking along the dashed line shown in (b).

A vertical section milled by focused ion beam (FIB) in the ultra-fine grained $\mathrm{Cu}-1 \mathrm{wt}$. \% $\mathrm{Pb}$ alloy is presented. Several micro-cracks are revealed which by inter-connection seem to follow a common crack propagation path (the dashed line in Fig. 3b). This microstructure feature provides, in our opinion, direct experimental support for our hypothesis/ analysis. The above 
picture also suggests that severe plastic deformation could make normally ductile materials behave in a brittle fashion when the extent of deformation, the grain size attained at a given temperature, strain/ strain rate and the density of dislocations reach an extreme range that promotes fracture processes. This view is in line with that of von Karman [66,67], who in a classic paper showed that depending on the experimental conditions (high tensile component of the stress system, high strain rate, high strain and/ or low temperature), even very ductile materials can become brittle, while it is also possible to extrude rock and marble by superimposing a sufficiently high hydrostatic (compressive and equal in all three directions) stress. In addition, it is consistent with the recent findings concerning nanocrystalline pure Pd and a Pd-10\% Au alloy, where extremely limited ductility was observed in tension [68]. We note also that the amount of the percolating porosity observed in UFG $\mathrm{Cu}-\mathrm{ppm}$ at most - may resolve an apparent contradiction between the observed ductile fracture of SPD materials (necking and ductile dimples) vs. their very small ductility (few per cent at the most).

In this model, the theoretical limit for the grain size attainable as a result of SPD depends on a material property $(G)$, a fracture property, $\gamma_{\mathrm{s}}$, and the plasticity parameters of tensile/ compressive stress for fracture, $\sigma_{y c}$, and the strengthening coefficient, $\kappa$, which, in turn, are heavily influenced by the processing variables of temperature, strain and strain rate.

The present model is not to be understood as an attempt to relate grain refinement to cavity/ crack formation (appearance of micro-cracks). Among the numerous research papers dealing with UFG materials produced by different SPD processing routes, cracks/cavities have been reported only in a few of them. Dynamic recovery/recrystallization processes, when present, facilitate further dislocation-based plasticity. Our model, by definition, relates the theoretical limit of grain refinement of an initially ductile metal to crack initiation at the stage where this material is not able to support further plastic deformation but demonstrates brittle-like fracture, at least locally. When dynamic recovery is present and the limit of plasticity is not 
reached, the grain size that will emerge with continued strain will be related to the sub-grain size corresponding to the magnitude of the steady state stress (as originally suggested by [69]). In addition, application of a hydrostatic pressure can suppress crack nucleation and propagation and a material with a smaller grain size than what is predicted by Eq. (3) may be produced. Alternatively, a change in the deformation route, e.g. sequential application of rolling and HPT, can provide an additional option for grain refinement, which will depend on the different stress systems to which the material is subjected at various stages.

\subsection{Hall-Petch relation in SPD-processed metals}

For the present model to be validated experimentally, the strengthening coefficient $\kappa$ and the yield stress corresponding to the near-terminal material state $\sigma_{y c}$ should be known. In the general case, both these parameters will have different values at different stages of the deformation history. In the literature, one can find indications that the Hall-Petch slope gradually decreases [41-43] or even becomes negative [44, 45] with decreasing grain size. Without going into details, we mention that four different concepts are typically invoked to explain such features. These are the models based on an analysis of dislocation activities, see e.g. [70-72], diffusioncontrolled processes [73], interplay of translational and rotational modes of deformation [74], GB sliding and shearing [75, 76], and a two-phase representation of a nanomaterial [77-79]. These theories attempt to explain mainly the inverse Hall-Petch relation, which may come into play at a grain size of 10-15 $\mathrm{nm}$ [44] and the models are usually concerned with grain sizes below $100 \mathrm{~nm}$.

In our present approach we consider sub-micrometer to $\mathrm{nm}$ - range grain size materials in which the Hall-Petch equation is obeyed throughout, albeit with different slopes corresponding to the material state. Some well-known results of the dislocation theory are used for this derivation and the details can be found, for example, in the book by Haasen [80]; see also Appendix A for some details. According to the general theory proposed for understanding the 
Hall-Petch behaviour, the interactions of a moving dislocation on a lattice plane are made up of three parts: a) the interaction between edge dislocations moving along parallel planes, b) the interaction between the dislocation under consideration and dislocations moving on planes inclined to the first plane so that these dislocations can interact with/ cut each other, and c) the "back-stress" due to the pile-up of dislocations in the plane of motion. In the classical derivation of the Hall-Petch relationship, only (c) is taken into account.

In our opinion the contributions from both (a) and (c) are important and their relative significance changes at different stages of deformation (Appendix A). In the early stages of SPD, say up to 4-6 passes of ECAP,

$$
\tau_{2}=\tau_{1}+\alpha_{2} \sqrt{N}+\tau_{1} m_{12} \sqrt{\frac{\lambda}{d}}
$$

will be the governing equation. Here, $\tau_{2}$ is the minimum stress necessary for the activation of a dislocation source in grain 2 for the given deformation state of the material and $m_{12}$ (the direction cosine) transforms the slip system from grain 1 to the appropriate one (slip system) in grain 2 , $\tau_{1}$ is the critical shear stress in grain $1, \lambda$ is the distance of the source from the pile-up and $\alpha_{2}=$ [(1/3) $G b] . ~ N$ denotes the dislocation density. However, at larger strains (say, after 8-12 passes of ECAP), when most of the dislocations in the grain interior would have moved into the narrow regions of the cell walls (due to the onset of significant recovery), the second term on the righthand side of eq. (4) would become negligible. This is because once these dislocations enter the cell walls they become a part of the cell boundary and increase the cell boundary misorientation. Therefore, it is clear that because $N$ is a function of grain size, when the dislocations are in the grain interior (up to 4-6 ECAP passes), the Hall-Petch slope would be greater than that beyond 4-6 ECAP passes (when a major portion of the dislocations would have moved into the cell walls). At the coarsest grain sizes (in the very early stages of SPD) also the value of $N$ is likely to be low. Then again the slope will be less than that after up to, say, 4-6 ECAP passes. Likewise, 
in the range where the dislocation density in the grain interior is less than after 4-6 passes (i.e., after $>6$ ECAP passes) the flow stress would be less than what would be obtained by extrapolating the Hall-Petch plot corresponding to the earlier region. Then, the plot over a wide range is likely to have a sigmoidal shape and this is what is observed experimentally as well as through MD simulations [3, 81-83]. Finally, the Hall-Petch equation is derived based on the concept of dislocation nucleation within the grains (Frank-Read sources). The stress necessary for this process becomes so enormous at very small grain sizes that below a certain grain size this mechanism will cease. It is logical that in that range the Hall-Petch relationship is not obeyed. There other processes like dislocation/ partial dislocation emission from grain boundaries, formation of deformation twins, grain boundary sliding etc. may take over. When none of these mechanisms are significant, fracture processes will be the sole way of relieving stress concentrations. The regions where the Hall-Petch relationship breaks down or an inverse Hall-Petch relationship is obeyed have been examined in several studies.

As indicated earlier, an alternative treatment of the Hall-Petch relation in terms of geometrically necessary dislocations etc. is possible and this will be taken up for investigation in the future. Here we have confined ourselves to the treatment of Haasen [80], which provides at least a semi-quantitative understanding of the experimentally observed change in the Hall-Petch slope.

A point is noteworthy. According to Eq. (4), a decrease in the effective Hall-Petch slope to zero would correspond to a yield stress independent of grain size $d_{c}$, which indicates the limit of the Hall-Petch type of relationship as well as the range of applicability of Cottrell's models used in this study.

In the following, we estimate the minimum grain size, which can be reached in copper and nickel, if the grain refinement is governed by Eq. (3). Following Dieter [51], who has based his conclusion on experimental data corresponding to many metals, the specific surface energy 
for brittle/ plasticity-induced fracture is taken as $\sim 1 \mathrm{~J} \mathrm{~m}^{-2}$. This value of $\gamma_{\mathrm{s}}$ was originally advocated by Orowan [84].

\subsection{Application of the model}

\subsubsection{Copper}

Coarse-grained material: The data from Chokshi et al. [85], who tested as-received, wrought OFHC copper of grain size ranging from about 6 to $25 \mu \mathrm{m}$ (not to be confused with the notso-dense nanostructured specimens produced by physical vapour deposition, also studied in the same paper) are used. From the graphs presented, where the grain size range is far coarser than the terminal, saturation grain size well inside the sub-micrometer range, one gets a mean $\sigma_{\mathrm{y}}$ value of 231.9 MPa and a Hall-Petch slope of $0.588 \mathrm{MPa} \cdot \mathrm{m}^{0.5}$. The shear modulus of copper is $48 \mathrm{GPa}$. This would suggest a minimum grain size of about $124 \mathrm{~nm}$ as the minimum theoretical grain size (Eq. (3)). This prediction is clearly below a value of about $200 \mathrm{~nm}$ reported by [86], who came to this conclusion after analysing the experimental results of many authors, which included studies in the sub-micrometer range. This result can be rationalized by noting that the value of $\kappa$ (and, as a consequence, the extrapolated value of $\sigma_{y c}$ ) starts decreasing from about one micrometer and the values of $\sigma_{\mathrm{yc}}$ and $\kappa$ used in this calculation are significantly different the realistic numbers corresponding to the sub-micrometer range.

ECAP-processed copper. The range of grain sizes studied covers typically values that vary from $100 \mu \mathrm{m}$ down to $400 \mathrm{~nm}$. From Mishra et al. [86], one also learns that according to most authors $\sigma_{y c}=450 \mathrm{MPa}$ for this metal. The average value of $\kappa$ for all the authors analysed by Mishra et al. (see Table 1 in [86]) is $2.96 \times 10^{-4} \mathrm{GPa} \cdot \mathrm{m}^{0.5}$. In that Table, when the paper of Wang and Murr [87], where the $\kappa$ value reported is much higher, is excluded, a value of $\kappa=2.25 \times 10^{-4} \mathrm{GPa} \cdot \mathrm{m}^{0.5}$ is obtained. Then minimum grain sizes of $129 \mathrm{~nm}$ and $224 \mathrm{~nm}$ respectively for the two cases are predicted. Evidently, the latter prediction is close to the experimental value of $200 \mathrm{~nm}$. Likewise, contrary to the findings of the others, $\mathrm{Xu}$ et al. [88] have reported a somewhat lower value of 
$\sigma_{y c}=400 \mathrm{MPa}$. For this case, the predicted value of minimum grain size is a somewhat higher, i.e., $284 \mathrm{~nm}$. These estimates reveal that the value of the saturation grain size is strongly affected by the values of $\sigma_{y c}$ and $\kappa$ chosen. Therefore, the development of a procedure for a priori determination of $\sigma_{y c}$ and $\kappa$ at the earliest will be extremely useful.

\subsubsection{Nickel}

Nanocrystalline nickel produced by repeated cold rolling and folding gives rise to one of the smallest grain sizes produced so far in pure metals [5]. The relevant data from the mechanical tests of Dinda [89] are used here: $\sigma_{y c}=2.17 \mathrm{GPa}, \kappa=0.35 \mathrm{MPa} \cdot \mathrm{m}^{0.5}$. The shear modulus of nickel is $76 \mathrm{GPa}$. Then, from Eq. (3) one obtains a value of about $10 \mathrm{~nm}$ as the minimum attainable grain size. This value is the same as the measured smallest grain size, which was about $10 \mathrm{~nm}$ (this is regarded as fortuitous, as some errors in the experimental inputs could have got cancelled; we just state that the prediction is good) [5]. This result also indicates why the (percolated) porosity was not observed in pure Ni deformed by ECAP [38], where the grain size was saturated at about $300 \mathrm{~nm}$.

Eq. (3) suggests that a smaller final grain size will be reached in materials with a lower value of the shear modulus $G$, if the other variables $\kappa$ and $\sigma_{y c}$ remain nearly constant. This observation is consistent with the easy amorphization seen in B2 NiTi during SPD [90, 91]. It also explains why even though the $G$ value is very similar for $\mathrm{Al}, \mathrm{Au}$ and $\mathrm{Ag}$, the terminal, saturation grain sizes are different, i.e., the latter value depends also on the magnitudes of $\kappa$ and $\sigma_{y c}$. Eq. (3) also suggests that larger values for the strengthening coefficient (work hardening) and the yield stress corresponding to a given material state will lead to a smaller final grain size. Thus, Eq. (3) can account for the observed differences in the grain refining capability of, e.g., pure $\mathrm{Ni}$ and $\mathrm{Cu}$.

\subsection{Required further development of the model}


In our model, the effects of stacking fault energy, chemical composition and the presence or absence of non-shearable particles in the material on the final grain size are captured into the maximum achievable stress before fracture processes are initiated, $\sigma_{y c}$ and the slope $\kappa$ of the Hall-Petch line.

Based on dislocation theory, one can say that a high stacking fault energy increases the tendency for cross-slip and hence is useful in reducing stress concentration and the stress level for a given deformation state of the material, i.e., it increases the final grain size obtainable. This argument is consistent with experimental results [92]. In contrast, alloying will decrease the final grain size, if the solute addition increases $\sigma_{y c}$ (e.g., alloys which give rise to solid solution strengthening, grain boundary pinning elements or those that lead to precipitation), but will increase it if the solute addition leads to a decrease of the yield stress. Of course, these two parameters are not unrelated. It is well known that alloying in quite a few cases changes the value of the stacking fault energy and the value of $\sigma_{y c}$. The presence of non-shearable particles usually increases the $\sigma_{y c}$ value and possibly also the slope of the Hall-Petch plot $(\kappa)$. Then, the terminal grain size obtainable will decrease. Finally, if twin formation is present as an important deformation mechanism, its presence will also be reflected in the value of the Hall-Petch slope and/ or the value of $\sigma_{y c}$.

The critical grain size $d_{\mathrm{c}}$, as defined by Eq. (3), is sensitive to the value of $\gamma_{s}$. Based on earlier works, in our estimates we used the fact that for most metallic materials under conditions of brittle fracture the specific surface energy $\gamma_{s}$ has a value of the order of $1 \mathrm{~J} \mathrm{~m}^{-1}$. This choice gives rise to excellent agreement with experimental results. But, it is safe to note that the theoretical grain size predicted will increase as the square of the increase in this value $\left(\gamma_{s}\right)$. In our model, therefore, $\gamma_{s}$ is regarded as a phenomenological constant.

A few additional points are also mentioned: 
1. The model is concerned with the prediction of the limiting/ final grain size beyond which more deformation does not lead to further grain refinement. Details of the evolution towards this final grain size, prior to the onset of the fracture processes, will have to be investigated separately and have already been the subject of many investigations.

2. Often, alloying makes the recovery and recrystallization processes more sluggish. Then, as a result of a postponement of the recovery processes, the final grain size obtainable in an alloy will be smaller than in a pure metal (due to an increase in the value of $\sigma_{y c}$ ). The experimentally observed effect of GB segregation [93] or fine precipitates [94] on the attainable grain size supports this view, see also $[95,96]$. The opposite would be true if alloying leads to acceleration in the recovery and recrystallization processes. However, one has to note that in addition alloying can induce GB segregation [93], hinder GB migration [94], form dislocation atmospheres [97], etc. All these will adversely affect the recovery processes.

3. Combination of several different straining routes represents a possibility to attain further grain refinement. This option may decrease the final grain size due to an increase in the HallPetch-slope and/ or the $\sigma_{\mathrm{yc}}$ value. This possibility has not yet been studied systematically.

\section{ECAP with application of back-pressure}

In the current model, formation of micro-cracks and their growth with increased deformation into propagating cracks and final fracture is considered as "the final response" of a material to an external stress, which leads to a reduction in the stress concentration. In our view, this fracture process defines the theoretical limit of grain refinement. Therefore, the application of a hydrostatic pressure should postpone crack nucleation and propagation and the superposition of a 
hydrostatic stress component can lead to some further grain refinement ${ }^{2}$. Presently, we shall analyse the influence of the so-called "back-pressure" (hydrostatic pressure) on the appearance of porosity in SPD-processed metals.

The extrusion load required for ECAP is estimated. (ECAP is taken as an example because the nature of metal flow, the stresses developed etc. have been well analysed for the extrusion process. Therefore, it is relatively easy to extend that analysis to the ECAP process. But, if the stresses developed, metal flow etc. in the other SPD processes also are known, the analysis can be modified to cover those SPD processes as well.) In this analysis, following earlier workers, the shear zone is assumed to be extremely narrow (tending to a line) and abrupt and the bend in the direction of flow is achieved across a single plane. Plastic flow changes direction at the meeting plane of the two intersecting arms of the extrusion set-up. The overall strain suffered by the billet at the various stages of deformation is considered and uniform straining is assumed. The last is a rather crude approximation in view of the presence of frictional and redundant work (but made in most of the earlier analyses also). Notwithstanding this, very meaningful predictions are obtained (see below). The material parameters and friction coefficient pertaining to the actual experimental conditions were used.

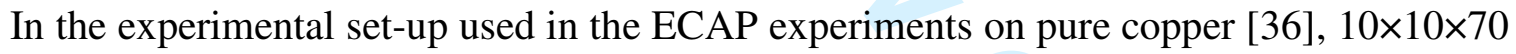
$\mathrm{mm}^{3}$ billets, well lubricated with $\mathrm{MoS}_{2}$, were pressed through a die of $90^{\circ}$ extrusion angle.

The present order of magnitude determination of the total extrusion load is based on the works of Siebel [98], Sachs [99], von Karman [66] and others and these are summarised elegantly by Lange [67] (see, in particular, Chapters 13 and 15). The total extrusion load consists of three components, viz., (a) the force needed for ideal deformation, (b) the force necessary to

\footnotetext{
${ }^{2}$ Under some deformation conditions, e.g. at an elevated temperature, the saturation grain size may be increased by the presence of recovery processes (including dynamic recrystallization, grain growth). Then, the crack forming
} 
overcome friction between the work-piece and the container wall, and (c) the force needed to shear the billet through an angle $2 \theta$, where $2 \theta$ is the extrusion angle. (A process analogous to the ECAP process has been known for quite a while in the mechanical engineering literature as "Side Extrusion" [67].) Again, following earlier work, sliding friction is assumed, i.e., Coulomb's law of friction is valid. (These conditions, however, will change to sticking friction at high homologous temperatures of deformation or very high strain rates, where significant adiabatic heating due to deformation will be present. There could also be intermediate situations where mixed friction conditions prevail.) As stated above, the assumption that shearing takes place along a single plane to change the direction of extrusion by an angle equal to $2 \theta$ is an approximation because in the real case the zone of shear has a certain length and width and the change in the direction of flow is achieved over an arc of deformation whose radius also could be an experimental variable. How such situations can be analysed is also discussed by Lange [67]. In this concept paper, we shall confine ourselves to a discussion of the simplified physical description presented above.

(a) Ideal force: Initially a billet of length $l_{0}$ and area of cross-section $A_{0}$ is compressed before it is subjected to shearing. The force necessary to complete the first stage of the operation (compression) is $\sigma_{\text {flow }, m} \cdot A_{0}$, where $\sigma_{\text {flow }, m}$ is the mean flow stress. (If $\sigma_{\text {flow }, 0}$ is the flow stress at the beginning of the operation and $\sigma_{f l o w, 1}$ is the value at the end of the operation, $\sigma_{\text {flow }, m}=\left(\sigma_{\text {flow }, 0}\right.$ $\left.\left.+\sigma_{f l o w, 1}\right) / 2\right)$

(b) Shear force: For the side extrusion of a solid as described above, this term will be equal to $(2 / 3) \cdot \theta \cdot \sigma_{f l o w, 1} \cdot A_{0}$ as the shearing takes place after the initial compression is complete. Here $\theta$ is expressed in radians (see Table 13.2 of Lange [67]).

\footnotetext{
tendency will be less than at ambient temperatures. Under those conditions, influence of the hydrostatic pressure on the final grain size would be less.
} 
(c) Surface Frictional force: This arises from the friction present between the extrusion container wall and the moving billet of cross-sectional area $A_{0}$, circumference $S$ and length $l_{0}$ in the course of the extrusion process. There are two components here arising from each of the two arms of the extrusion die that are joined together to achieve a final ECAP (extrusion) direction at an angle $2 \theta$ to the original direction. Evidently, for the first part the appropriate flow stress is $\sigma_{f l o w, m}$ and for the second part the value is $\sigma_{f l o w, 1}$. From Coulomb's law of friction, the frictional stresses in the two segments are $\mu \sigma_{f l o w, m}$ and $\mu \sigma_{f l o w, 1}$ respectively. Then, the total frictional force is $\mu \sigma_{\text {flow }, m} S l_{0}+\mu \sigma_{\text {flow }, 1} S l_{0}\left(S=10 \times 10 \mathrm{~mm}^{2}\right.$ and $l_{0}=70 \mathrm{~mm}$ in our experiments $)$.

Combining the three contributions, the total extrusion force is obtained as

$$
P_{\text {tot }}=\sigma_{\text {flow }, m} A_{0}+(2 / 3) \theta \sigma_{\text {flow }, 1} A_{0}+\mu \sigma_{\text {flow }, m} S l_{0}+\mu \sigma_{\text {flow }, 1} S l_{0} .
$$

For our experiments, the estimates are arrived at using the following values: $\sigma_{f l o w, 0}=150$ $\mathrm{MPa}, \sigma_{f l o w, 1}=350 \mathrm{MPa}$, and thus, $\sigma_{\text {flow }, m}=250 \mathrm{MPa}$; coefficient of friction $\mu=0.1$ and $2 \theta=90^{\circ}$. Using these values in the above equation for the total extrusion load, one obtains a value of 0.21 MN. The ECAP deformation was done at a stress of $2 \mathrm{GPa}$. For a billet cross-section of $10 \times 10$ $\mathrm{mm}^{2}$, this works out to a total extrusion load of $0.20 \mathrm{MN}$ (the experimental value). Evidently the agreement between the calculated and the experimental values is good.

As radiotracer experiments have revealed, percolating porosity is developed during ECAP, carried out without the application of a back-pressure. Now, the minimum back-pressure necessary to avoid micro-crack formation during ECAP will be derived.

According to Lange (see footnote on p. 15.20 in Ref. [67]) in the direct extrusion process a cylindrical state of stress is present, where $\sigma_{z}$ is the extrusion stress and the radial stress $\sigma_{r}=$ the tangential stress $\sigma_{t}$. It has also been concluded that $\sigma_{r} \approx 0.75 \sigma_{z}$. For the ECAP deformation in our study $\sigma_{z}=2 \mathrm{GPa}$. Therefore, $\sigma_{r}=1.5 \mathrm{GPa}$.

Using Mohr's circle construction and the von Mises yield criterion (it is equally easy to use other yield criteria like Tresca, Mohr- Coulomb, Drucker-Prager or Gurson) one obtains that 
the maximum shear stress, $\tau_{\max }$, acting on the material during ECAP in the absence of a backstress is

$$
\tau_{\max }=\left(\frac{\sigma_{z}-\sigma_{r}}{2}\right)=0.250 \mathrm{GPa} \text { or } 250 \mathrm{MPa}
$$

Based on the works of Cottrell (whose theory of plasticity-induceed fracture was used above) and others, Dieter [51] has suggested that micro-cavities first form in those locations of a material where the maximum shear stress equals or exceeds its shear yield stress.

But, the mean tensile flow stress of the material itself is only $250 \mathrm{MPa}$. Therefore, based on experiments it could be said that this ECAP material has a shear yield stress of $250 / \sqrt{3}=144$ $\mathrm{MPa}$ only. As the maximum shear stress that develops in the material during ECAP of $250 \mathrm{MPa}$ (see above) is greater than the shear yield stress of $144 \mathrm{MPa}$, when ECAP is carried out without the application of a back-stress, percolated micro-cavities are likely to be formed. This prediction is borne out by experiments [29, 34].

Now, when a back-pressure of $200 \mathrm{MPa}$ is applied, again using Mohr's circle construction and von Mises yield criterion, one calculates the maximum shear stress that develops during ECAP as $\tau_{\max }=(2-0.2-1.5) / 2 \mathrm{GPa}=0.150 \mathrm{GPa}$ or $150 \mathrm{MPa}$, which is very close to (actually slightly more than) the shear yield stress of the ECAP material of $144 \mathrm{MPa}$. Then, it follows that no micro-cracks is likely to be produced (and hence there is no chance of the micro-cracks to percolate) during an ECAP operation, where the yield stresses before and after ECAP are very close to the values given above and a back-pressure of the given magnitude (or greater) is applied. This is what is observed experimentally [36].

Evidently, the magnitude of the hydrostatic stress necessary to prevent crack formation is related to a) the total strain, b) the strain rate (range), and c) the strain path (torsion, shear, tension and/ or compression). In this method, based on the Internal Variable Approach [100], the 
effects of all these parameters are captured into the maximum local stress tensor, which, in turn, determines the magnitude of the hydrostatic component of the stress system.

Micro-cracks, even when they are introduced through dislocation accumulation at barriers, may be closed during subsequent deformation, especially under a high value of the hydrostatic component of the applied stress. This feature agrees well with the absence of connected porosity in ECAP-deformed $\mathrm{Cu}$ with the application of a pre-calibrated back-pressure or HPT-processed $\mathrm{Cu}$ [36]. Proper deformation conditions can heal/ prevent the formation of cavity/crack-like defects, which could be introduced during the severe plastic deformation of an UFG material. This healing process is facilitated by the inherent ductility of metallic materials.

\section{Concluding Remarks}

In an earlier work [34], radiotracer measurements revealed unambiguously that percolating porosity develops even in ductile copper under certain conditions of severe plastic deformation. These findings underline the importance of crack formation and propagation during SPD of ductile metals as they reach the limit of their plastic deformation potential and/ or encounter unfavourable conditions of deformation. In our view this is a concomitant of SPD processing and has been used to determine the finest, theoretical grain size obtainable. But, we also emphasize that by careful design it is possible to carry out SPD operations, without cavity formation. Then, the final grain size that will develop is likely to be greater than the theoretical, limiting value estimated here.

A model has been developed, which describes the response of an UFG metal in terms of dislocation-mediated deformation processes, which towards the limits of severe plastic deformation or under unfavourable experimental conditions gives rise to percolating cavity formation. The magnitudes of certain directly measurable variables determine the theoretical, 
limiting smallest grain size that can be obtained. Such a description allows the prediction of some important features of SPD-processing in a simple and elegant way. The order of magnitude calculations predict smallest grain size of about 220-230 nm for ECAP-deformed $\mathrm{Cu}$ and of about $10 \mathrm{~nm}$ for pure Ni deformed by accumulated rolling and folding. These values agree well with the experimental results. According to the proposed model, the maximum possible grain refinement is largely determined by the strengthening coefficient and the maximum attainable yield stress, which are the two constants of the Hall-Petch relation. These are determined experimentally in the present stage of development of the ideas.

The model results in a correlation among three, apparently independent, phenomenological parameters - the limiting grain size $d_{\mathrm{c}}, \sigma_{\mathrm{yc}}$ and $\kappa$. Good agreement between the model predictions and the experiments suggests that these parameters are actually interdependent and this is an important inference from the model.

The hydrostatic component of the stress system suppresses crack propagation and enhances the deformability of the UFG material. Therefore, the post-SPD treatment could be critical, as, for example, indicated by the appearance of percolating porosity in ECAP-processed $\mathrm{Ni}$ after a heat treatment [38]. The present estimate of the critical value of the back-pressure needed to prevent percolated cavity formation during the ECAP deformation of pure $\mathrm{Cu}$ agrees well with the experimental results.

In summary, the present approach, which invokes the use only of microstructure features for which there is unequivocal experimental evidence, is able to quantitatively explain some of the prominent aspects of the severe plastic deformation process such as the existence of a limit in grain size refinement despite further continued deformation, load necessary to carry out the ECAP process and the minimum back-stress needed to eliminate the formation of percolating micro-cavities. In addition, the approach can also explain characteristics such as the formation of and separation between ultrafast transport pathways in SPD-treated materials and this will be 
considered in a separate publication. Finally, quantitative guidance concerning the choice of processing conditions and routes that avoid the formation of meso-scale or micro-scale defects such as connected internal porosity is provided.

\section{Acknowledgements}

The authors thank Prof. Dr. G. Gottstein for a stimulating discussion. KAP thanks the DFG for the provision of a Mercator Professorship. Financial support of the DFG (Deutsche Forschungsgemeinschaft) through a research grant is also acknowledged.

\section{References}

[1] R.Z. Valiev, M.J. Zehetbauer, Y. Estrin, H.W. Höppel, Y. Ivanisenko, H. Hahn, G. Wilde, H.J. Roven, X. Sauvage and T.G. Langdon, Adv. Engn. Mater. 9 (2007) p.527.

[2] R.Z. Valiev, Nature Mater. 3 (2004) p.511.

[3] K.S. Raju, M.G. Krishna, K.A. Padmanabhan, V.S. Sarma, N. P. Gurao and G. Wilde, J. Mater. Sci. 46 (2011) p.2662.

[4] X. Huang, G. Winther, N. Hansen, T. Hebesberger, A. Vorhauer, R. Pippan and M. Zehetbauer, Mater. Sci. Forum 426-432 (2003) p. 2819.

[5] G.P. Dinda, H. Rösner and G. Wilde, Scr. Mater. 52 (2005) p.577.

[6] D. Geist, C. Rentenberger and H.P. Karnthaler, Acta Mater. 59 (2011) p. 4578.

[7] A.A. Nazarov, A. E. Romanov and R.Z. Valiev, Acta Metall. Mater. 41 (1993) p.1033.

[8] T. Hebesberger, H.P. Stüwe, A. Vorhauer, F. Wetscher and R. Pippan, Acta Mater. 53 (2005) p.393.

[9] A. Bachmaier, A. Hohenwarter and R. Pippan, Scr. Mater. 61 (2009) p.1016.

[10] R. Pippan, F. Wetscher, M. Hafok, A. Vorhauer and I. Sabirov, Adv. Engineer. Mater. 8 (2006) p.1046. 
[11] X. Molodova, A. Khorashadizadeh, G. Gottstein, M. Winning and R.J. Hellmig, Int. J. Mater. Res. 98 (2007) p.269.

[12] G. Wilde, N. Boucharat, G.P. Dinda, H. Rösner and R.Z. Valiev, Mater. Sci. Forum 503-504 (2005) p.425.

[13] A.P. Zhilyaev and T.G. Langdon, Progr. Mater. Sci. 53 (2008) p.893.

[14] K. Oh-ishi, Z. Horita, D.J. Smitz, R.Z. Valiev, M. Nemoto and T.G. Langdon, J. Mater. Sci. 14 (1999) p.4200.

[15] V.V. Rybin, High Plastic Deformation and Fracture of Metals, Metallurgia, Moscow, 1986 (in Russian).

[16] V.I. Kopylov and V.N. Chuvil'deev, in Nanostructured Materials by High-Pressure Severe Plastic Deformation, NATO Science Series II: Mathematics, Physics and Chemistry, 212 (2006) p.69.

[17] T.S. Orlova, A.A. Nazarov, N.A. Enikeev, I.V. Alexandrov, R.Z. Valiev and A.E. Romanov, Physics of the Solid State 47 (2005) p.845.

[18] A.M. Glezer, Bull. Russ. Acad. Science. 71 (2007) p.1722.

[19] T.G. Langdon, Mater. Sci. Eng. A 462 (2007) p.3.

[20] I.J. Beyerlein, R.A. Lebensohn and C.N. Tome, Mater. Sci. Eng. A 345 (2003) p.122.

[21] J.W. Signorelli, P.A. Turner, V. Sordi, M. Ferrante, E.A. Vieira and R.E. Bolmaro, Scripta Mater. 55 (2006) p.1099.

[22] F.A. Mohamed, Acta Mater. 51 (2003) p.4107.

[23] W. Blum, Y.J. Li and K. Durst, Acta Mater. 57 (2009) p.5207.

[24] Y.J. Li, X.H. Zeng and W. Blum, Acta Mater. 52 (2004) p.5009.

[25] M.J. Zehetbauer, L.F. Zeipper and E. Schafler, in Nanostructured Materials by HighPressure Severe Plastic Deformation, NATO Science Series II: Mathematics, Physics and Chemistry, 212 (2006) p.217. 
[26] M.A. Meyers, V.F. Nesterenko, J.C. LaSalvia and Q. Xue, Mater. Sci. Eng. A 317 (2001) p.204.

[27] A.A. Nazarov, A.E. Romanov and R.Z. Valiev, Nanostructured Mater 6 (1995) p.775.

[28] S.V. Divinski, J. Ribbe, D. Baither, G. Schmitz, G. Reglitz, H. Rösner, K. Sato, Y. Estrin and G. Wilde, Acta Mater. 57 (2009) p.5706.

[29] S.V. Divinski, J. Ribbe, G. Reglitz, Y. Estrin and G. Wilde, J. Appl. Phys. 106 (2009) 063502.

[30] Y. Amouyal, S.V. Divinski, Y. Estrin and E. Rabkin, Acta Mater. 55 (2007) p.5968.

[31] J. Ribbe, G. Schmitz, Y. Estrin and S.V. Divinski, Defect Diffusion Forum 289-292 (2009) p.95.

[32] S.V. Divinski and G. Wilde, Mater. Sci. Forum 584-586 (2008) p.1012.

[33] I. Kaur, Yu. Mishin and W. Gust, Fundamentals of GB diffusion and interphase boundary diffusion, Wiley, $3^{\text {rd }}$ ed. (1995).

[34] J. Ribbe, D. Baither, G. Schmitz and S.V. Divinski, Phys. Rev. Lett. 102 (2009) 165501.

[35] J. Ribbe, D. Baither, G. Schmitz and S.V. Divinski, Scr. Mater. 61 (2009) p.129.

[37] G. Wilde, J. Ribbe, G. Reglitz, M. Wegner, H. Rösner, Y. Estrin, M.J. Zehetbauer, D. Setman and S.V. Divinski, Adv. Eng. Mater. 12 (2010) p.758.

[37] A.H. Cottrell, Trans. Metal. Soc. AIME 212 (1958) p.192.

[38] S.V. Divinski, G. Reglitz, Y. Estrin and G. Wilde, Acta Mater. 59 (2011) p.1974.

[39] E.O. Hall, Proc. Phys. Soc. London B 64 (1951) p.747.

[40] N.J. Petch, J. Iron Steel Inst. 174 (1953) p.25.

[41] G.W. Nieman, J.R. Weertman and R.W. Siegel, Scr. Metall. 23 (1989) p.2013.

[42] A.M. El-Sherik, U. Erb, G. Palumbo and K.T. Aust, Scr. Met. Mater. 27 (1992) p.1185. 
[43] V.Y. Gertsman, M. Hoffmann, H. Gleiter and R. Birringer, Acta Metall. Mater. 42 (1994) p.3539.

[44] X. Zhang, H. Wang, R.O. Scattergood, J. Narayan, C.C. Koch, A.V. Sergueeva and A.K. Mukherjee, Acta Mater. 50 (2002) p.4823.

[45] K.A. Padmanabhan, G.P. Dinda, H. Hahn and H. Gleiter, Mater. Sci. Eng A 452-453 (2007) p.462.

[46] E. Anderson, D.L.W. King and J. Spreadborough, Trans. TMS-AIME 242 (1968) p.115.

[47] A.W. Thompson, Acta Met. 23 (1975) p.1337.

[48] G.E. Fougere, J.R. Weertman and R.W. Siegel, Nanostructured Mater. 3 (1993) p.379.

[49] S. Takeuchi, Scr. Mater., 44 (2001) p.1483.

[50] N. Tsuji, Y. Ito, Y. Saito and Y. Minamino, Scr. Mater. 47 (2002) p.893.

[51] G.E. Dieter, Mechanical metallurgy (3rd ed.), McGraw-Hill, New York, 1986.

[52] X. Molodova, G. Gottstein, M. Winning and R.J. Hellmig, Mater. Sci. Eng. A 460-461 (2007) p.204.

[53] D. Hull, Introduction to Dislocations, Pergamon, 1968, pp.100-103.

[54] K.A. Padmanabhan, R.A. Vasin and F.U. Enikeev, Superplastic Flow: Phenomenology and Mechanics, Springer Verlag, Heidelberg-Berlin (2001).

[55] D. Kiener, M. Rester, S. Scheriau, B. Yang, R. Pippan and G. Dehm, Int. J. Mater. Res. 98 (2007) p.1047.

[56] J.Y. Huang, Y.T. Zhu, H. Jiang and T.C. Lowe, Acta Mater. 49 (2001) p.1497.

[57] K.N. Braszczyjska-Malik, L. Lityjska and W. Baliga, J. Microscopy 224 (2006) p.15.

[58] M.F. Ashby, Phil. Mag. 21 (1970) p.399.

[59] U.F. Kocks, J. Eng. Mater. Technol. 98 (1976) p.76.

[60] J.P. Hirth, Metall. Trans. A 3 (1972) p.3047.

[61] Y. Estrin and H. Mecking, Acta Metall. 32 (1984) p.57. 
[62] Y. Estrin and H.S. Kim, J. Mater. Sci. 42 (2007) p.9092.

[63] M. Zehetbauer, Acta metall. mater. 41 (1993) p.589.

[64] H.J. Frost and M.F. Ashby, Deformation Mechanism Maps, Pergamon, Oxford, U. K., 1982.

[65] S.H. Kang, Y.S. Lee and J.H. Lee, J. Mater. Process. Technol. 201 (2008), p.436.

[66] T.Z. von Karman, Ver. Deutsch. Ing. Forschungsheft 118 (1912) p.37.

[67] K. Lange, Handbook of Metal Forming, Society of Manufacturing Engineers, Michigan, USA, 1985.

[68] H. Rösner, N. Boucharat, J. Markmann, K.A. Padmanabhan and G. Wilde, Mater. Sci. Eng. A 525 (2009) p.102.

[69] O.D. Sherby and P.M. Burke, Prog. Mater. Sci. 13 (1967) p.325.

[70] C.E. Carlton and P.J. Ferreira, Acta Mater. 55 (2007) p.3749.

[71] R.O. Scattergood and C.C. Koch, Scr. Metall. Mater. 27 (1992) p.1195.

[72] B. Lian, B. Buadelet and A.A. Nazarov, Mater. Sci. Eng. A 172 (1993) p.23.

[73] R.A. Masumura, P.M. Hazzledine and C.S. Pande, Acta Metall. 13 (1998) p.4527.

[74] A.L. Kolesnikova, I.A. Ovid'ko and A.E. Romanov, Techn. Physics Letters 33 (2007) p.641.

[75] H. Hahn and K.A. Padmanabhan, Phil. Mag. B 76 (1997) p.559.

[76] V. Yamakov, D. Wolf, S.R. Phillpot, A.K. Mukherjee and H. Gleiter, Nat. Mater. 3 (2004) p.43.

[77] P.P. Chattopadhyay, S.K. Pabi and I. Manna, Mater. Chem. Phys. 68 (2001) p.80.

[78] N. Wang, Z. Wang, T. Aust and U. Erb, Acta Metall Mater 43 (1995) p.519.

[79] D.A. Konstantinidis and E.C. Aifantis, Nanostruct. Mater. 10 (1998) p.1111.

[80] P. Haasen, Physical Metallurgy, English Translation by J Mordike, Cambridge University Press, 1978, pp.251; 281.

[81] W.J. Kim, Scr. Mater. 61 (2009) p.652. 
[82] A.C. Lund and C.A. Schuh, Acta Mater. 53 (2005) p.3193.

[83] K.S. Raju, M.G. Krishna, K.A. Padmanabhan, V.S. Sarma, N. Gurao and G. Wilde, Mater. Sci. Eng. A 491 (2008) p.1.

[84] E. Orowan, Fatigue and Fracture of Metals, Symposium at Massachusetts Institute of Technology, John Wiley \& sons, New York, USA (1952).

[85] A.H. Chokshi, A. Rosen, J. Karch and H. Gleiter, Scr. Metall. 23 (1989) p.1679.

[86] A. Mishra, B.K. Kad, F. Gregori and M.A. Meyers, Acta Mater. 55 (2007) p.13.

[87] S. Wang and I.E. Murr, Metall 13 (1980) p.203.

[88] C. Xu, M. Furukawa, Z. Horita and T.G. Langdon, in Nanomaterials by Severe Plastic Deformation, Z. Horita, ed., Fukuoka, Japan (2005) p.19.

[89] G.P. Dinda, Nonequilibrium processing of amorphous and nanostructured materials, $\mathrm{PhD}$ thesis, Saarland University, 2006.

[90] M. Peterlechner, T. Waitz and H.P. Karnthaler, Scr. Mater. 60 (2009) p.1137.

[91] J. Koike, D.M. Parkin and M. Nastasi, J. Mater. Res. 5 (1990) p.1414.

[92] Y.H. Zhao, X.L. Liao, Y.T. Zhu, Z. Horita and T.G. Langdon, Mater. Sci. Eng. A 410$411(2005)$ p.188.

[93] G. Nurislamova, X. Sauvage, M. Murashkin, R. Islamgaliev, R. Valiev, Phil. Mag. Lett. 88 (2008) p. 459.

[94] R. Pippan, S. Scheriau, A. Taylor, M. Hafok, A. Hohenwarter and A. Bachmaier, Ann. Rev. Mater. Res. 40 (2010) p. 319.

[95] D.G. Morris, M.A. Munoz-Morris, Acta Mater. 50 (2002) p. 4047.

[96] Y. Huang, J.D. Robson, P.B. Prangnell, J. Mater. Sci. 45 (2010) p. 4851.

[97] E. Nes, K. Marthinsen, Mater. Sci. Eng. A 322 (2002) p. 76.

[98] E. Siebel, Metal Forming in Plastic Condition, Verlag Stahleisen, Düsseldorf, 1932.

[99] G. Sachs, Z. Angew. Math. Mech. 7 (1927) p.235. 
[100] Y.N. Robotnov, Fundamental Problems in Visco-Plasticity, in Recent Advances in Applied Mechanics, Academic Press, New York, NY, 1969.

[101] T. Narutani and J. Takamura, Acta Mater. 39 (1991) p.2037. 


\section{Appendix: Interactions of a moving dislocation}

The interactions of a lattice dislocation moving on a lattice plane consist of three different contributions [80]:

(a) Interaction between edge dislocations moving along parallel planes. This gives rise to a "passing stress" of magnitude $\tau_{p}=\left(\frac{G b}{8 \pi(1-v) z_{0}}\right)$, where $\mathrm{z}_{0}$, the separation between the parallel slip planes, decreases with increasing dislocation density, $N$, according to the relation $z_{0}$ $\propto N^{-0.5} ; b$ is the Burgers vector and $v$ is the Poisson ratio. That is,

$$
\tau_{p}=\alpha_{1} G b \sqrt{N} ; \alpha_{1} \approx\left(\frac{1}{3}\right) ; \text { i.e., } \tau_{p}=\alpha_{2} \sqrt{N}
$$

where $\alpha_{2}=(1 / 3) G b$. This contribution to the yield stress will be present as long as dislocations are present inside the grains and not just in the narrow regions of the cell walls. With respect to severe plastic deformation this would mean the early passes, say up to 4-6 passes. In this region the Bailey-Hirsch equation $\tau_{\text {flow }}=\tau_{0}+\beta G b \sqrt{N}$ should be obeyed. Narutani and Takamura [101] in an experimental study involving nickel subjected to monotonic uni-axial stressing at $77 \mathrm{~K}$ and $295 \mathrm{~K}$ to strains in the range of 2.5 to $20 \%$ have concluded that their experimental results are consistent with the trend predicted by the Bailey-Hirsch model. It is noted that the grain size in that study was in the $\mu \mathrm{m}$-range.

After a higher number of passes, say, 8-12, recovery processes are present in a very prominent manner and a significant part of the dislocations in the grain interior would have moved into the narrow regions of the cell walls. In this range, which can be understood, in principle, in terms of the models of Kocks [59], Estrin and Mecking [60] and Ashby [58] or refinements thereof, recovery processes compete with dislocation multiplication and lead to the near-absence of dislocations in the grain interior. In this range, the importance / relevance of Eq. (A.1) would be lost. In a conventional derivation of the Hall-Petch relationship, contribution 
from this "passing stress" term is not taken into account at any stage (see, for example, Haasen [80]). Here we have improved that analysis in this aspect.

(b) Interaction between the dislocation under consideration and perpendicular dislocations, i.e., cutting of forest dislocations. Energy to create kinks and jogs and for the production of vacancies associated with the movement of jogs in screws: Separation " $l$ " of the "trees" decreases with increasing dislocation density $N_{\mathrm{F}}$ of the forest according to $l \propto N_{\mathrm{F}}^{-0.5}$. The upper limit of the flow stress necessary to cut through the forest of dislocations (the Orowan stress) is given by

$$
\tau_{l}=\alpha_{3} G b \sqrt{N_{F}}=\alpha_{4} \sqrt{N_{F}}
$$

where $\alpha_{3}$ and $\alpha_{4}$ are constants. Normally $N_{\mathrm{F}}$ is proportional to $N$. It is clear from the experimental results of Narutani and Takamura [101] that practically all forest dislocations are present only in the narrow regions of cell walls; in any case definitely beyond about $2.5 \%$ strain when the presence of the cells have been observed experimentally. Therefore, the contribution to the flow stress from this term can be neglected without introducing serious errors.

(c) For ensuring plastic flow in grain 1 in which the dislocation under consideration is present, stress also has to be applied to overcome the "back stress" due to the pile-up of dislocations in the plane of motion of the dislocation that will develop on deformation beyond the initial yield point. The Hall-Petch relationship is obtained usually by taking this feature/ aspect alone into account [80]. Two assumptions in this derivation are $(i)$ that high-angle boundaries define the grain size, and (ii) that the texture present in the material is random.

Dislocation pile-up at the boundary of the first grain leads to a stress concentration given by

$$
\tau(x)=\tau_{a} \sqrt{\left(\frac{2 a}{x-a}\right)}
$$


where $|x|>a$, with " $a$ " equalling the radius of the circular portion of the plane occupied by the dislocations. When there are $\mathrm{n}$ dislocations in the pile-up, $\tau_{a}$ will be replaced by the total effective stress needed to overcome the obstacle, i.e., $\left(n \tau_{a}\right)$.

Dislocation pile-up at a boundary of the first grain leads to a stress concentration at that boundary. When this stress concentration reaches a value $\tau_{2}$ corresponding to the stress required for a Frank-Read source to become operational in the neighbouring grain on a slip system appropriate to its orientation with respect to the common boundary, dislocation motion (slip) will get initiated in/ transmitted to the second grain. If $\lambda$ is the distance of the source from the pile-up, from Eq. (A.3) one obtains

$$
\left(\tau_{2}-\tau_{1}\right) \sqrt{\frac{d}{\lambda}}=\tau_{1} m_{12} \quad \text { or } \quad \tau_{2}=\tau_{1}+\tau_{1} m_{12} \sqrt{\frac{\lambda}{d}}
$$

where $\tau_{1}$ is the critical shear stress in grain $1, \tau_{2}$ is the minimum stress necessary for the activation of a dislocation source in grain 2 for the given deformation state of the material and $m_{12}$ (the direction cosine) transforms the slip from grain 1 to grain 2. Equation (A.4) is the wellknown Hall-Petch equation, Eq. (1). 


\section{List of figures}

Figure 1: Cottrell's model [37] for plasticity-induced cracking process: Coalescence of two slip directions (a) to form a cracked dislocation on a cleavage plane (b); and coalescence of two slip bands (c) to form a cleavage crack (d). This model was derived for BCC metals [37, 51].

Figure 2: Formation of a Lomer-Cottrell sessile dislocation in FCC metals, a) - c) (after Hull [53]).

Figure 3: $\mathrm{SEM}$ image of a vertical section of ECAP-deformed $\mathrm{Cu}-1 \mathrm{wt} . \% \mathrm{~Pb}$ alloy produced by $\mathrm{FIB}$; a chain of micro-cracks is observed (a). The microstructure may be interpreted as a consequence of cracking along the dashed line shown in (b). 

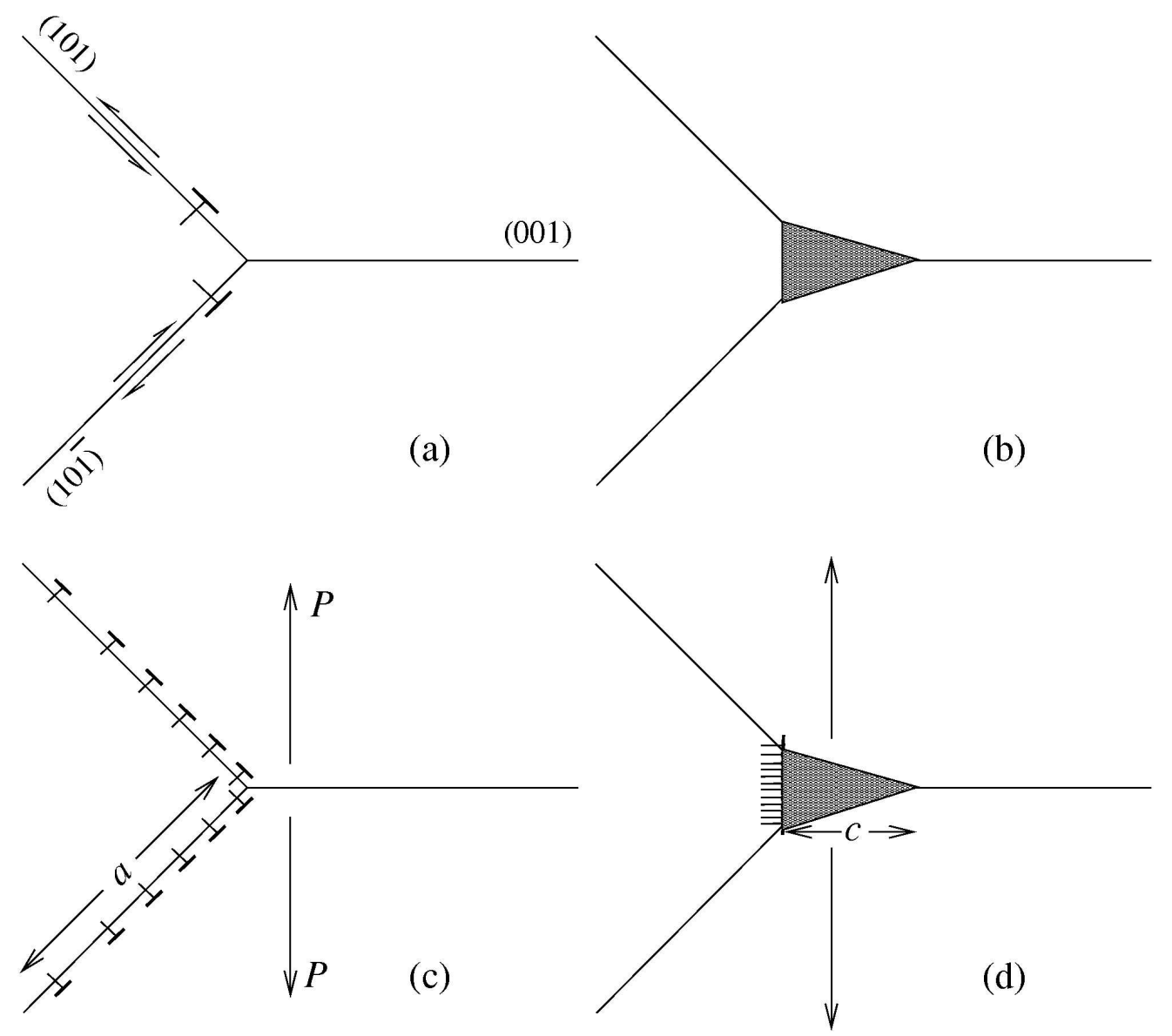

Cottrell's model [31] for plasticity-induced cracking process: Coalescence of two slip directions (a) to form a cracked dislocation on a cleavage plane (b); and coalescence of two slip bands (c) to form a cleavage crack (d). This model, derived for BCC metals originally, is now regarded as valid for other metals also under conditions where their plasticity gets severely restricted $[31,40]$. $628 \times 569 \mathrm{~mm}(80 \times 80 \mathrm{DPI})$ 

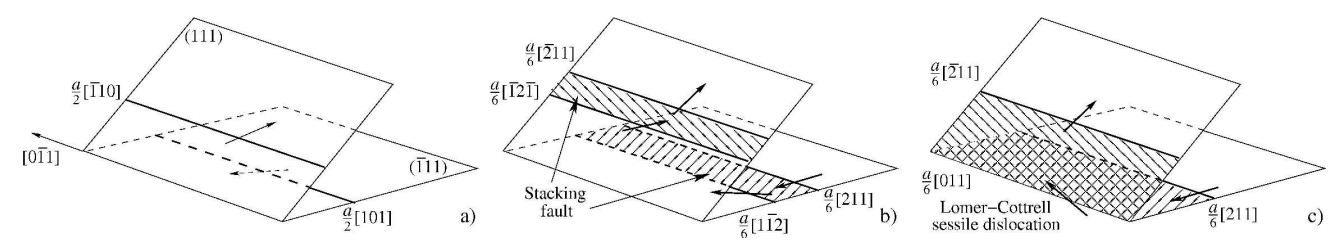

$1474 \times 249 \mathrm{~mm}(80 \times 80 \mathrm{DPI})$ 
1

2

3

4

5

6

7

8

9

10

11

12

13

14

15

16

17

18

19

20

21

22

23

24

25

26

27

28

29

30

31

32

33

34

35

36

37

38

39

40

41

42

43

44

45

46

47

48

49

50

51

52

53

54

55

56

57

58

59

60

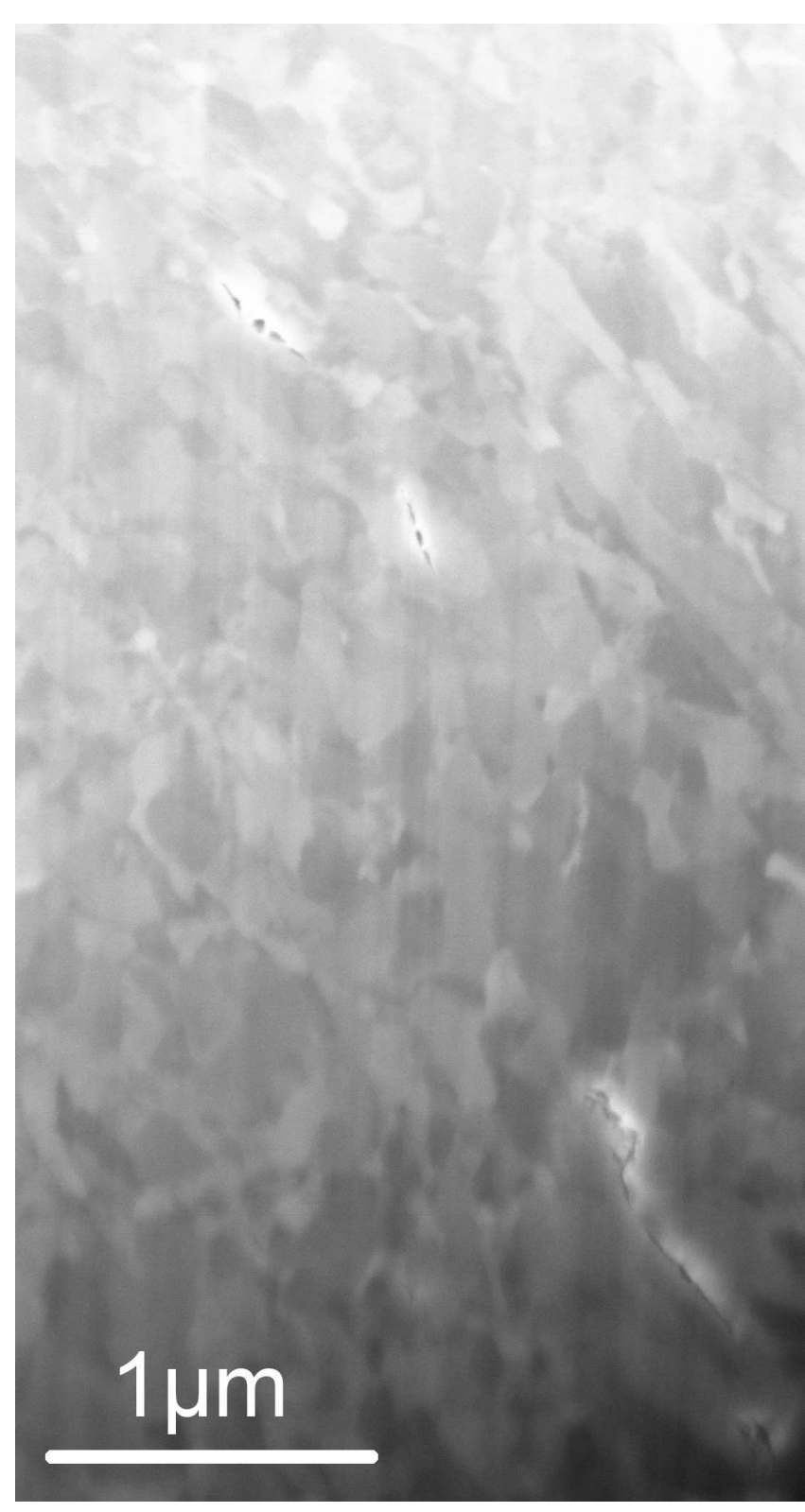

$388 \times 728 \mathrm{~mm}(72 \times 72 \mathrm{DPI})$ 
SEM image of a vertical section of ECAP-deformed $\mathrm{Cu}-1$ wt. \% Pb alloy produced by FIB; a chain of micro-cracks is observed (a). The microstructure may be interpreted as a consequence of cracking along the dashed line shown in (b). $388 \times 728 \mathrm{~mm}(72 \times 72 \mathrm{DPI})$ 